\title{
Correlation between heavy metal concentration and oxidative potential of street dust
}

\author{
Mohammad Malakootian ${ }^{1,2} \cdot$ Amir Mohammadi $^{3} \cdot$ Alireza Nasiri $^{1} \cdot$ Gea Oliveri Conti ${ }^{4} \cdot$ Maryam Faraji $^{1,2}$ (i)
}

Received: 22 September 2021 / Accepted: 10 November 2021 / Published online: 28 November 2021

(c) The Author(s), under exclusive licence to Springer Nature B.V. 2021

\begin{abstract}
The current study aimed to consider oxidative potential (OP), its spatial distribution, and correlations with heavy metals (HMs) in street dust in Kerman city, Iran. The concentration of HMs in 35 street dust samples was detected by ICPAES. The OP in samples was measured through dithiothreitol (DTT). The mean concentration of elements followed $\mathrm{Zn}>\mathrm{Cu}>\mathrm{Pb}>\mathrm{Cr}>\mathrm{As}>\mathrm{Cd}$. The OP value was found to be $7.17 \pm 2.98 \mathrm{nmol} / \mathrm{min}$. $\mu \mathrm{g}$ dust in the current study. A strong correlation was observed among the concentrations of $\mathrm{As}$ and $\mathrm{Cr}$ and $\mathrm{OP}$ values in dust samples. More values of OP were observed in the center and west of the Kerman city. According to results of the current study, it could be concluded that OP can be applied as metrics of pollution originated from different sources and human health effects. The amount of OP in the street dust in the Kerman city can be reduced through the use of clean fuels.
\end{abstract}

Keywords Street dust $\cdot$ Heavy metals $\cdot$ Oxidative potential $\cdot$ Dithiothreitol $\cdot$ Acellular chemical test

\section{Introduction}

Street dust is considered as the contaminated medium that originated from the natural and anthropogenic sources included soil and sand, traffic and vehicle transformation, deposition of atmospheric particles, construction or industrial activities, and mining (Al-Khashman 2004, Wang et al. 2021). Components of street dust include a wide range of pollutants, for instance, pesticides, polycyclic aromatic hydrocarbons (PAHs), microplastics, and heavy metals (Konstantinova et al. 2020, Nematollahi et al. 2020, Patchaiyappan et al. 2021). However, the highest

Maryam Faraji

m.faraji@kmu.ac.ir; m_faraji28@yahoo.com

1 Environmental Health Engineering Research Center, Kerman University of Medical Sciences, Kerman, Iran

2 Department of Environmental Health Engineering, Faculty of Public Health, Kerman University of Medical Sciences, Kerman, Iran

3 Department of Public Health, School of Nursing and Midwifery, Maragheh University of Medical Sciences, Maragheh, Iran

4 Department of Medical Sciences, Surgical and Advanced Technologies "G.F. Ingrassia,", University of Catania, Catania, Italy attention has concentrated on the potentially toxic elements (PTEs), especially for heavy metals such as $\mathrm{Hg}, \mathrm{Ni}, \mathrm{Cu}$, $\mathrm{Pb}, \mathrm{Cd}, \mathrm{Zn}, \mathrm{Cd}, \mathrm{Cr}, \mathrm{As}, \mathrm{V}$, and Mn (Santo Signorelli et al. 2019, Moradi et al. 2020). The source of the street dusts can affect their composition. In urban dust, $\mathrm{Ca}, \mathrm{V}$, and $\mathrm{Mg}$ had more concentrations with respect to the background soil (Cesari et al. 2012). There are recommendations for the maximum permissible values of some heavy metals in air and soil, but did not define for street dust (Aguilera et al. 2021). The well-known characteristics of PTEs in the street dust as well as airborne particulate matter are nondegradability and accumulation in fatty tissues and other human organs and possibility of resuspension (Mohammadi et al. 2019; Dytłow and Górka-Kostrubiec 2020, OsorioMartinez et al. 2021). Exposure to the PTEs may cause several unfavorable health effects such as cardiovascular (Khaniabadi et al. 2017), respiratory, and neurodegenerative diseases (Islam 2017; Singh et al. 2019). The oxidative stress related to PTEs exposure can result to the production of reactive oxygen species (ROS) within the target cells (Jantzen et al. 2018). The oxidative potential (OP) has been known as the intrinsic measure of the capability of PTEs to oxidize goal molecules and ROS production. Generation of ROS is considered as one of the key mechanisms by which particulate matter (PM) contains various pollutants such as PTEs can cause adverse biological effects 
leading to oxidative stress responses and several chronic and acute systemic inflammations. Oxidative stress in biological systems has been contributed to the cell damages due to the genotoxicity and cytotoxic mechanisms (Massimi et al. 2020). Acellular OP assays can estimate the PM ability to oxidize target molecules (Manigrasso et al. 2020). OP was measured in the previous studies, mainly in the airborne PM and limitedly in the street dust samples. In Lecce (Southern Italy), OP relationship investigated with ecotoxicological and cytotoxicological possible of $\mathrm{PM}_{10}$. Their finding indicated that toxicity bioassays dependent to time and dose. Also, statistically significant correlation was found between $\mathrm{OP}$ and $\mathrm{PM}_{10}$ concentration (Lionetto et al. 2019). Cesari et al. analyzed ions, metals, carbonaceous components, and OP activity with the DTT (dithiotreitol) assay in $\mathrm{PM}_{2.5}$ samples in an industrial suburban site in south Italy. Source apportionment showed that OP normalized in volume $\left(\mathrm{DTT}_{\mathrm{V}}\right)$ was related to the carbonaceous components, $\mathrm{NO}_{3}{ }^{-}$and $\mathrm{Ca}^{2+}$. These components indicated that the OP activity may associate to the release of PM from combustion and crustal (Cesari et al. 2019). In a study in London, UK, from 2002 to 2006, OP of $\mathrm{PM}_{10}$ measures and spatiotemporal trend predicted using land-use regression model. Results proposed that $\mathrm{PM}_{10}$ released from traffic, specially brake and tire wear, lead a higher OP than that from other emissions in 50-100 m of roadways (Yanosky et al. 2012). Pant et al. analyzed the chemical composition of road dust samples ( $\mathrm{PM}_{10}$ and bulk road dust) and OP in the samples from highway and road tunnel sites in Birmingham, UK, and heavily trafficked site in New Delhi of India. In this study, $\mathrm{Cu}$ reported as highlight PTEs related OP (Pant et al. 2015). In Salento's peninsula, in the Central Mediterranean in Italy, OP of $\mathrm{PM}_{10}$ measured and assessed relation between chemical composition and meteorological parameters with OP. It reported strong correlation OP with $\mathrm{Ba}, \mathrm{Ce}, \mathrm{Cr}, \mathrm{Cu}, \mathrm{Fe}$, and $\mathrm{Mn}$ in autumn-winter and also good correlation between $\mathrm{OP}$ with $\mathrm{Cu}, \mathrm{Mn}, \mathrm{P}$, and $\mathrm{Pb}$ in summer and spring. The sources of PTEs emissions mentioned traffic, combustion emissions, secondary aerosols, and re-suspended soil (Pietrogrande et al. 2018). Chemical composition and $\mathrm{OP}$ in $\mathrm{PM}_{10}$ assessed in dust storm and common days in Tehran, a populated city in Middle East. The highest amount of OP is reported on non-dusty days. Also, OP was significantly related to $\mathrm{Cu}, \mathrm{Ba}, \mathrm{Cd}, \mathrm{Mn}, \mathrm{Ni}$, $\mathrm{V}$, and $\mathrm{Fe}$ (Rezaei et al. 2018). Kerman city as metropolis has numerous streets and mining industries. Also, there is natural dust storm named 120-day wind Sistan yearly in this urban area (Malakootian et al. 2021). The main aim of this study was to (1) determine OP values in the street dust as new metrics of environmental pollution through acellular experiments; (2) investigate correlation between chemical composition of the street dusts and OP values; and (3) compare OP contents and risk related to the exposure to the
PTEs in street dust done in the previous study for the first time in Kerman city.

\section{Materials and methods}

\section{Study area}

Study area was Kerman city ( $30^{\circ} 28^{\prime}$ N, $57^{\circ} 08^{\prime}$ E) (Fig. 1) situated in the southeast of Iran and the capital of Kerman province with the population of 738000 people (Statistical, Center et al. 2016). It is located $1756 \mathrm{~m}$ above sea level. The mean temperature in Kerman city is $-8^{\circ} \mathrm{C}$ and $37^{\circ} \mathrm{C}$ in winter and summer, respectively.

\section{Dust sampling}

Thirty five dust samples included 200 to $250 \mathrm{~g}$, composed of three subsamples, were collected from a 0.5 square meter in the different points (see Fig. 1) by a brush and plastic dustpan (Abbasi et al. 2020, Naraki et al. 2021) from the streets or pavement edges in September of 2020. Samples were stored in the clear polyethylene bags. They were transported to the laboratory and analyzed. A nonindustrial area was selected as the background point.

\section{Chemical analyses}

Chemical analysis on the samples for measuring elements was described in the previous study in detail (Malakootian et al. 2021). The street dust samples were dried at room temperature and mechanically sieved through a $75-\mu \mathrm{m}$ nylon mesh. Mass of particles were measured after sieving through a $75-\mu \mathrm{m}$ nylon mesh. Analyses were restricted to $75-\mu \mathrm{m}$ fine particles. Pre-digestion was done for $2 \mathrm{~h}$ at $50{ }^{\circ} \mathrm{C}$ by ratio of $9: 3: 1$ of $\mathrm{HNO} 370 \%, \mathrm{HCl} 70 \%$, and $\mathrm{HF} 40 \%$. After that, digested samples were mineralized in $170{ }^{\circ} \mathrm{C}$ during $4 \mathrm{~h}$ in the Teflon high-pressure digestion vials (Applied Plastics Technology, Inc., Bristol, USA). Then, $2 \mathrm{~mL} \mathrm{H}_{2} \mathrm{O}_{2} 30 \%$ and $3 \mathrm{~mL}$ concentrated $\mathrm{HNO}_{3}$ were added to the cooled mineralized samples, and then they were diluted to $50 \mathrm{~mL}$ by Milli-Q water. Samples were filtered by a microporous membrane with the pore size of $0.45 \mu \mathrm{m}$ into a PET bottle. The concentration of HMs included $\mathrm{As}, \mathrm{Cd}, \mathrm{Cr}$, Copper $(\mathrm{Cu}), \mathrm{Pb}$, and $\mathrm{Zinc}(\mathrm{Zn})$ in the street dust samples which were measured using the inductively coupled plasma equipped atomic emission spectrometry detector (ICP-AES, Model: Arcos, Germany), according to the USEPA methodologies (Malakootian et al. 2021). 
Fig. 1 Study area map and sampling points

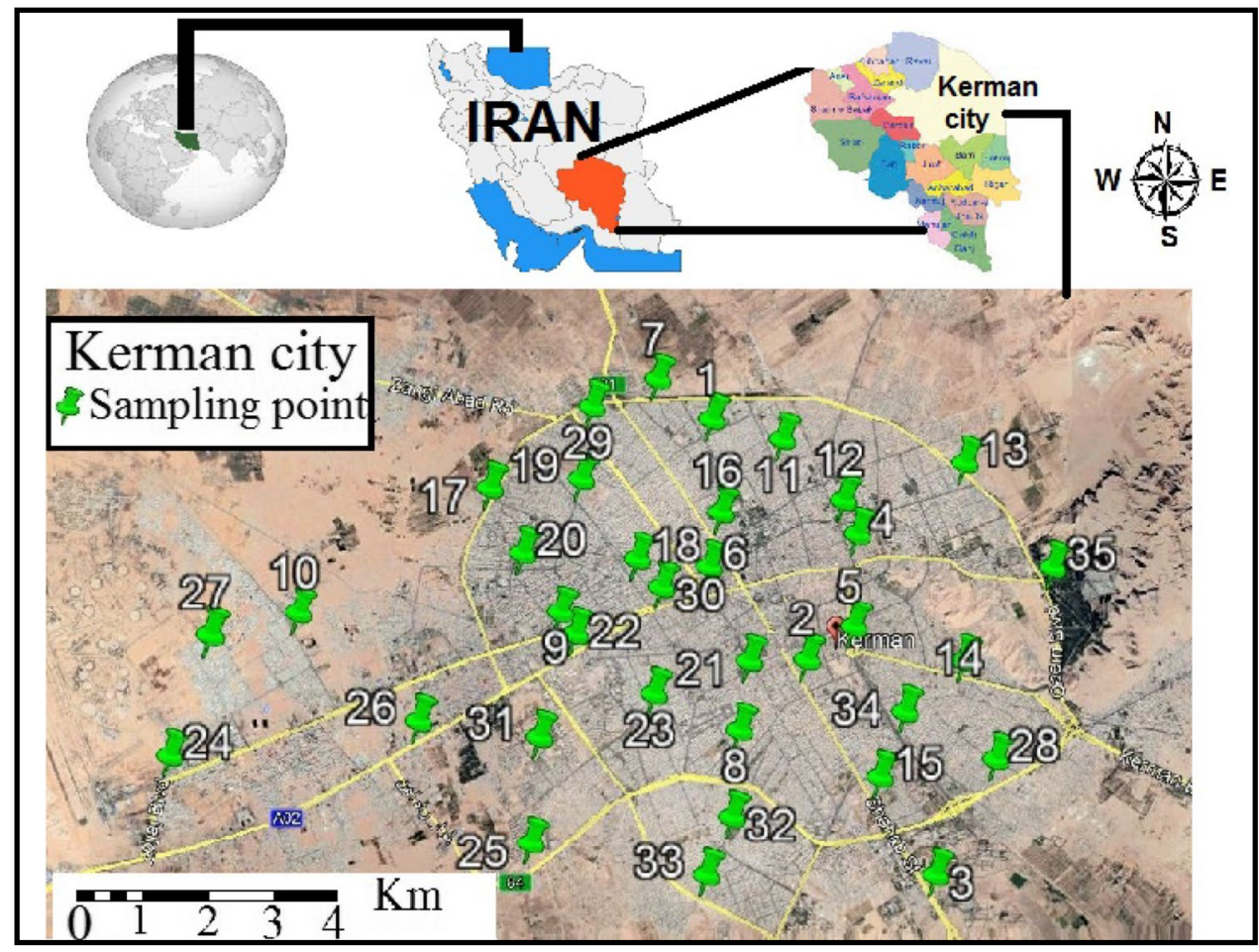

\section{Oxidation potential analysis}

Extraction of the $75-\mu \mathrm{m}$ fine particles was done using methanol. Extracted samples were sonicated in a water bath ultrasonic (Elmasonic) at $130 \mathrm{kHz}$ for $30 \mathrm{~min}$ (Naraki et al. 2021). They then passed through PTFE filters (Jet Biofil $-0.22 \mu \mathrm{m})$. OP in the samples was measured through acellular dithiothreitol (DTT) assay that described in the study by Lin et al., Ma et al., and Rezaei et al. (Lin and $\mathrm{Yu}$ 2011; Ma et al. 2018, Rezaei et al. 2018). All used chemicals included potassium phosphate buffer $(0.1 \mathrm{M})$ at $\mathrm{pH} 7.5$ treated with Chelex 100 resin, DTT, trichloroacetic (TCA), 5,5'-dithiobis(2-nitrobenzoic acid) (DTNB), and Tris base were obtained from Merck Company (Darmstadt, Germany). The absorption value was measured through the UV-VIS spectrophotometer (Shimadzu, UV-2550) at a wavelength of $412 \mathrm{~nm}$ and plotted versus time. The consumption of DTT (nmol/min) was calculated using Eq. (1):

$\mathrm{DTT}=\mathrm{Abs} \bullet \frac{n D T T}{A b s_{0}}$

where:

Abs $=$ Slope of curve absorbance versus time

$\mathrm{N}_{0}=$ Number of DTT initial moles (nmol)

$\mathrm{Abs}_{0}=$ Intercept of curve absorbance versus time

The DTT consumption was converted to DTT activity representative of OP value ( $\mathrm{nmol} / \mathrm{min} . \mu \mathrm{g}$ dust) through Eq. (2):
DTT activity $=\frac{D T T_{\text {sample }}-D T T_{\text {blank }}}{\text { Mass of Street Dust, } \mu g}$

\section{Data quality assurance and quality control (QA/QC)}

Quality assurance (QA) and quality control (QC) were provided through triplicate samples, blank and spike samples, and certified reference materials. The recovery efficiency was obtained to be $87-95 \%$. The limit of detection (LOD) was obtained to be three times of standard deviation of blank sample values. The amounts of LOD were obtained to be $0.5,0.10,1,1,1$, and $1 \mathrm{mg} / \mathrm{kg}$ for $\mathrm{As}, \mathrm{Cd}, \mathrm{Cr}, \mathrm{Cu}, \mathrm{Pb}$, and $\mathrm{Zn}$ and $0.05 \mathrm{nmol} / \mathrm{min}$ for $\mathrm{OP}$.

\section{Statistical analysis}

The data were analyzed by descriptive statistics and reported as mean \pm standard deviation. Data normality was investigated by Fligner test. Mean of concentrations was compared through analysis of variance (ANOVA) test. Pearson's correlation coefficient was used to assess correlation between HMs concentration and OP values. Statistical analyses were done in $\mathrm{R}$ software version 4.0.5. A $p$ value less than 0.05 was considered as the significant level. Spatial variations of the OP values was demonstrated through ArcGIS 10.1. Independent raster layers for OP were made by the interpolation method of Kriging. 


\section{Results and discussion}

\section{Value of HMs}

Box plot of HM concentrations in street dust $(\mathrm{mg} /$ $\mathrm{kg}$ ) is shown in Fig. 2. According to the study results, mean concentrations of elements followed the order of $\mathrm{Zn}>\mathrm{Cu}>\mathrm{Pb}>\mathrm{Cr}>\mathrm{As}>\mathrm{Cd}$. Background concentration of the HMs studied in the current study was found to be 12.10 , $0.33,35.90,15.85,16.40$, and $60 \mathrm{mg} / \mathrm{kg}$ for $\mathrm{As}, \mathrm{Cd}, \mathrm{Cr}, \mathrm{Cu}$, $\mathrm{Pb}$, and $\mathrm{Zn}$, respectively. So, the mean concentration of $\mathrm{Cu}$, $\mathrm{Pb}$, and $\mathrm{Zn}$ was approximately estimated to be 5, 3, and 3 times more than their background concentration, respectively. Source and spatial distribution of the elements were discussed in the previous study (Malakootian et al. 2021). The mean concentration of As was equal to its value in the background soil. As value in the street dust samples in Tehran, the capital of Iran, was reported about $6 \mathrm{mg} / \mathrm{kg}$ (Taghavi et al. 2019). The sources of As could be associated to the natural sources, particularly from deserts and agricultural or industrial activities (Atapour 2015). The mean concentration of $\mathrm{Cd}$ was similar to its value in the background sampling point $(0.34 \mathrm{mg} / \mathrm{kg})$. Cr had the maximum content of $35 \mathrm{mg} /$ $\mathrm{kg}$ equal to its value in the background soil. It was reported the mean concentration of $\mathrm{Cr}$ equal to $36.9 \mathrm{mg} / \mathrm{kg}$ in topsoil around Kerman in the study by Atapour (Atapour 2015). The maximum concentration of $\mathrm{Cu}(148 \mathrm{mg} / \mathrm{kg})$ in the western part of Kerman could be associated to the copper industry situated in this section. The mean concentration of $\mathrm{Pb}$ in the samples was found to be $46 \mathrm{mg} / \mathrm{kg}$. The highest value of $\mathrm{Pb}$

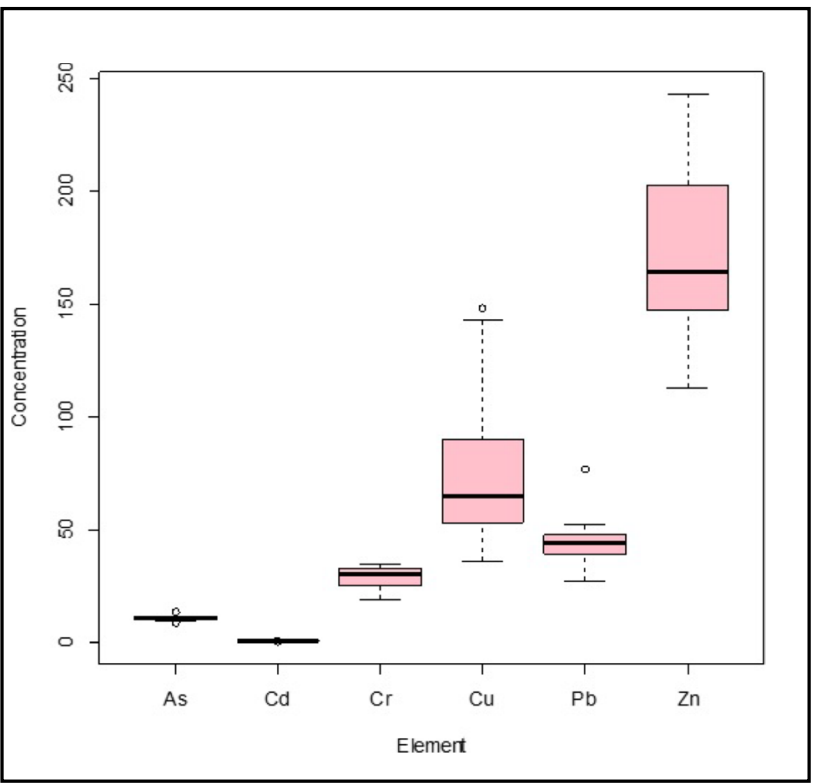

Fig. 2 Box plot of HM concentrations in street dust (mg/kg)
$(148 \mathrm{mg} / \mathrm{kg}$ ) was obtained in the sampling points located in the central streets due to the high traffic and the low velocity of local winds in this section of Kerman city. The highest value of $\mathrm{Zn}(243 \mathrm{mg} / \mathrm{kg})$ were reported in the city center with the high traffic. Also, sampling points close to gasoline stations had the more $\mathrm{Zn}$ concentrations. Similar results were found in the study of Hamzeh et al. about the urban soil and street dust in Tehran and Kerman (Hamzeh et al. 2011). The releases of $\mathrm{Zn}$ may be related to the tire friction (Taghavi et al. 2019), gasoline stations, and processing centers of vehicle battery (Safiur Rahman et al. 2019).

Natural sources such as local soil, traffic, and industrial activities especially mining could be considered as the key origins of HMs in the studied street dusts samples. Also, the 120-day wind Sistan is considered as another natural source that it is a strong summer wind occurring from late May to late September in the east and southeast of the Iran, particularly the Sistan Basin. It often accompanied by sand and dust storms (Malakootian et al. 2021).

\section{Oxidative potential values}

Descriptive analysis of OP value (nmol/min. $\mu \mathrm{g}$ dust) in street dust samples is reported in Table 1. The amount of OP was $7.17 \pm 2.98 \mathrm{nmol} / \mathrm{min} . \mu \mathrm{g}$ dust in the current study. Minimum and maximum of $\mathrm{OP}$ values were found to be 1.20 and $11.60 \mathrm{nmol} / \mathrm{min} . \mu \mathrm{g}$ dust. Pant et al. examined the OP of road dust in the samples collected from high traffic locations in Birmingham, UK. They were found the higher OP for the bulk street dust compared to its $\mathrm{PM}_{10}$ component. Maximum depletion per $\mu$ g particles was found $0.14 \%$ for bulk road dust in terms of OP associated with glutathione depletion $\left(\mathrm{OP}_{\mathrm{GSH}}\right)$ (Pant et al. 2015). In the study by Chirizzi et al. on the effect of carbon content existed in the Saharan dust on oxidative potential of water-soluble fractions of PM 2.5 and $\mathrm{PM}_{10}$ through DTT assay, DTT activity of PM 2.5 was more than $\mathrm{PM}_{10}$ (Chirizzi et al. 2017). In the characterization and comparison of water-soluble $\mathrm{PM}_{2.5}$ oxidative potential assessed by DTT assay by Gao et al., OP content was correlated to the some water-soluble metals including $\mathrm{Fe}$ and $\mathrm{Cu}$, organic compounds, and antagonistic metal-organic and metal-metal interactions (Gao et al. 2020).

Table 1 Descriptive analysis of oxidative potential value (nmol/ min. $\mu \mathrm{g}$ dust) in the investigated street dust samples

\begin{tabular}{ll}
\hline OP value (nmol/min. $\mu g$ dust) \\
\hline Min & 1.20 \\
1st quartile & 5.00 \\
Median & 7.40 \\
Mean & 7.17 \\
Standard deviation & 2.98 \\
3rd quartile & 9.40 \\
Max & 11.60 \\
\hline
\end{tabular}


It is thought chemical component of particles can be affect its toxicity. Redox active trace metals (e.g., $\mathrm{Cu}, \mathrm{Zn}, \mathrm{Ni}$ ) and polycyclic aromatic hydrocarbons (PAHs) can generated ROS, inflammatory responses and stress oxidative (Pant et al. 2015; Ferrante et al. 2017). In the study by Rezaei et al. on the physiochemical features and OP of outdoor air particulate matter in two conditions dust storm days and regular days in Tehran, the capital of Iran and one of the most polluted cities in the world, OP values measured through DTT were, respectively, reported to be $12.8 \pm 6.38,12.3 \pm 3.21$, and $27.6 \pm 5.31 \mathrm{nmol} / \mathrm{min} . \mu \mathrm{g} \mathrm{PM}_{10}$ in dusty, inversion, and regular days in urban areas (Rezaei et al. 2018). It could be declared that the particles (street dust or airborne) in more polluted cities may be have more OP values due to presence of the compounds that are redox active.

\section{Correlation of HMs and oxidative potential values}

Correlation coefficients between oxidative potential values and studied HMs in street dust samples are reported in Fig. 3. These results were shown a strong significant correlation between As $(r=0.59)$ and $\mathrm{Cr}(r=0.42)$. Numerous studies have reported a significant correlation between OP and the concentration of transition metals in ambient particulate samples, including Fe (Kelly et al. 2011), Fe, $\mathrm{Cu}$ (Yang et al. 2014), and Fe, Pb (Godri et al. 2010). In the study by Pant et al., no significant relationships were observed between elements and $\mathrm{OP}_{\mathrm{GSH}}$ for either $\mathrm{PM}_{10}$

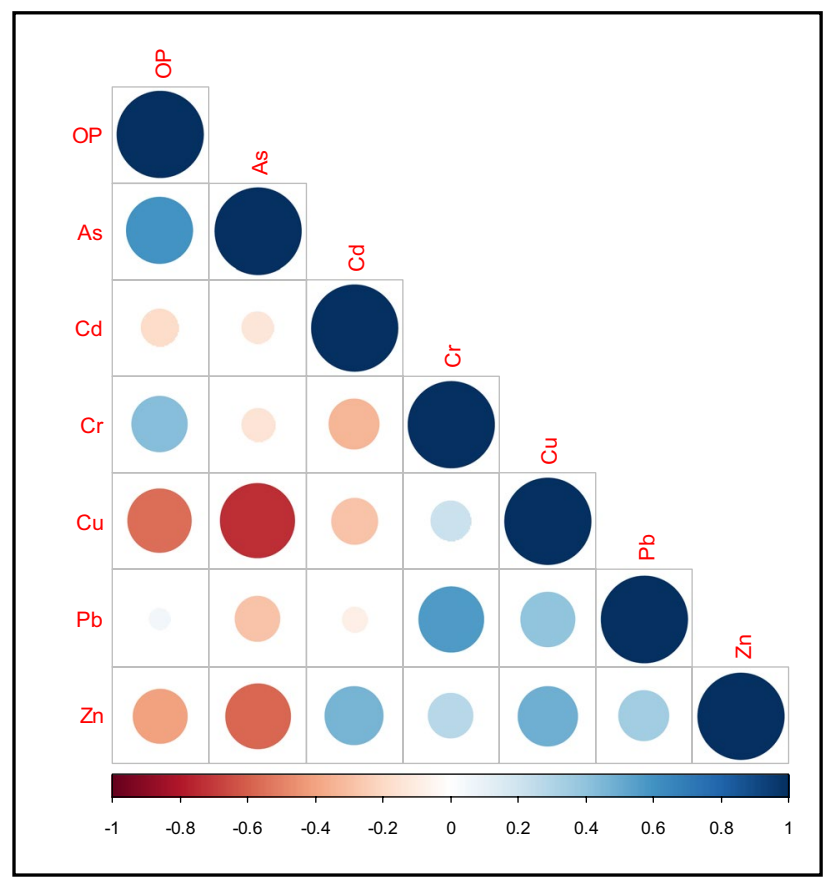

Fig. 3 Correlation coefficients between oxidative potential values and studied HMs in street dust samples or bulk street dust. It was shown the strong correlation between $\mathrm{Cu}$ and $\mathrm{Mn}$ and the moderate correlation among $\mathrm{Ba}, \mathrm{Cd}, \mathrm{Ba}, \mathrm{Ni}, \mathrm{V}, \mathrm{Fe}$, and $\mathrm{OP}$ in airborne particulate matters in the study by Rezaei et al. (Rezaei et al. 2018). As we mentioned, elements of As and $\mathrm{Cr}$ had more correlation coefficient with $\mathrm{OP}$ values in the current study (Malakootian et al. 2021). We assessed human health risk associated to the HMs existed in the street dust samples in Kerman city in the previous study. In comparison between health risk related to the HMs and their correlation with $\mathrm{OP}$ value, it can be concluded that $\mathrm{As}$ and $\mathrm{Cr}$ had a more non-carcinogenic (HQ, hazard quotient) and carcinogenic risk (ELCR, excess lifetime cancer risk) from the main route, i.e., ingestion rout. $\mathrm{HQ}_{\mathrm{ing}}$ was found to be 0.1 and 0.026 for As and $\mathrm{Cr}$, respectively. ELCRing was obtained $4.71 \times 10^{-5}$ and $3.87 \times 10^{-5}$ for $\mathrm{As}$ and $\mathrm{Cr}$, respectively, that were more than other elements. Therefore, results from acellular chemical experiments in the OP study and from risk assessment model were compatible with each other. Consistent with this result, OP can be used as the appropriate index to examine the pollution status and human risk in different areas.

\section{Spatial trend of oxidative potential values}

According to the spatial trend of OP in the studied area in Fig. 4, it can be stated that more OP was observed in the center and western part of Kerman city. As discussed on the correlation between HM concentration and OP, a strong significant correlation was observed between As and $\mathrm{Cr}$. So, we must explore the sources of $\mathrm{As}$ and $\mathrm{Cr}$ in the center and west of the city to attenuate OP values in the street dust in the Kerman city. In the present study, a part of As could be released from natural sources, mainly in the west of city that it has been exposed to dust storms. The sources of As in the center of the Kerman city could be related to both natural sources (local soil and 120-day wind Sistan) and anthropogenic sources such as vehicle traffic (Malakootian et al. 2021). Numerous studies confirmed that releases of motor vehicles can be the main origins of $\mathrm{Cr}$ in street dust in the urbans (Lu et al. 2017; Shi and Lu 2018). Also, mining activities may be considered as the key sources of $\mathrm{Cr}$ in the street dust samples in the current study. In our previous study, street dust samples related to the western part of Kerman had the potential ecological risk (PER) values more than other parts. Also, dust samples collected from the center of Kerman indicated maximum non-carcinogenic risk (Malakootian et al. 2021). The high level of pollution in the western and center part of Kerman city could be due to the development of city and heavily loaded streets in these areas. 
Fig. 4 Spatial trend of oxidative potential values in the studied area

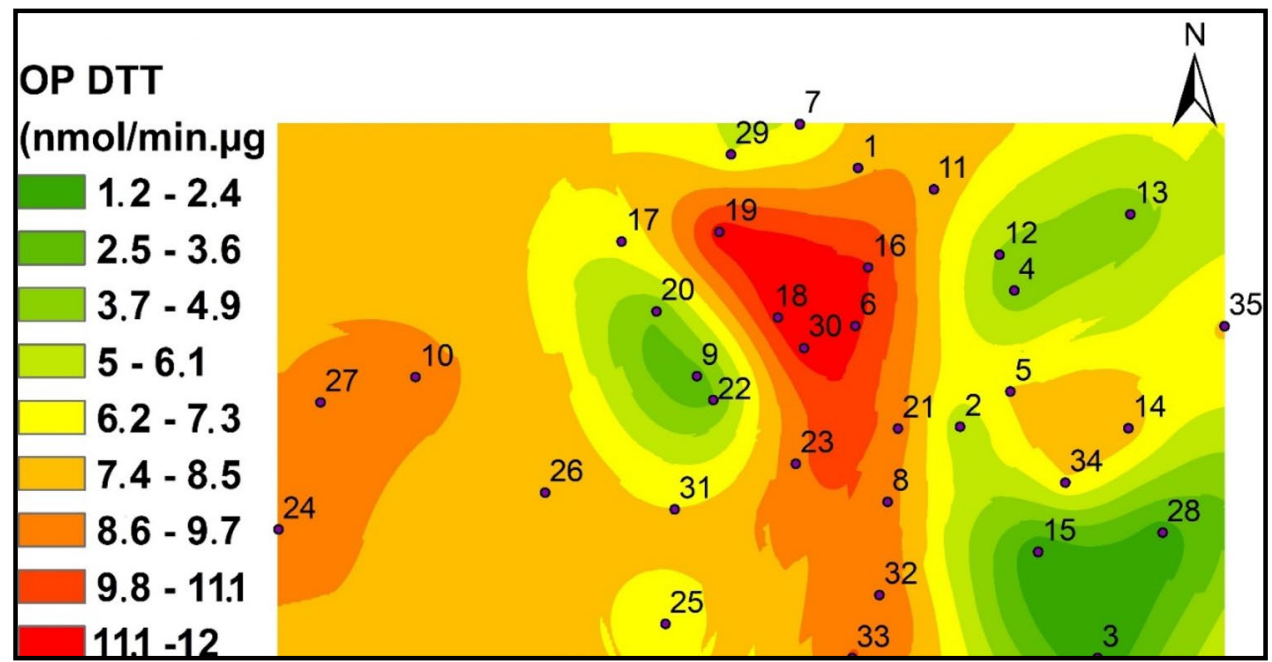

\section{Conclusion}

The aim of the present study was to explore OP, its spatial variations, and correlation with HMs in the street dust in Kerman city, Iran. As mentioned, a strong correlation was observed between As and $\mathrm{Cr}$ and OP content in dust samples. Also, both As and $\mathrm{Cr}$ had a more human health risk (non-carcinogenic and carcinogenic) compared to other HMs as we investigated in the previous study. Based on the spatial distribution of OP in the Kerman city, it can be declared that more values of OP were observed in the center and west of the Kerman city. Samples from these area indicated maximum human and ecological risk content. Therefore, OP could be used as the appropriate index to examine the pollution status and human and ecological risk in different areas. The design policies, green actions, and strategies, for improving the public health and welfare, emphasize that the connections between planning and actions of urban context and public health is vital for societies. It is very important to improve these aspects to avoid a large number of preventable diseases in urban population.

It must be mentioned that sampling was done in September of 2020 during COVID-19 pandemic that lead to a reduction of emissions due to restriction policies enforced by the government. So, results could be affected by this condition, and less pollution was obtained in the present study compare to the natural situation. We recommended this point will be considered in the generalizing the results to the normal conditions and comparing our results with future studies.

Acknowledgements The authors would like to acknowledge the Environmental Health Engineering Research Center of Kerman University of Medical Sciences for financial supports.

Author contribution Mohammad Malakootian: conceptualization, writing original MS, reviewing and editing of the MS. Amir Mohammadi: formal analysis, writing original MS, reviewing and editing of the MS. Alireza Nasiri: reviewing and editing of the MS. Gea Oliveri Conti: reviewing and editing of the MS. Maryam Faraji: supervision, project administration, investigation and performing the experiments, reviewing and editing of the MS.

Funding This work was supported by the Vice-Chancellor for Research and Technology of Kerman University of Medical Sciences under grant number 98000810 .

Availability of data and material Not applicable.

Code availability Not applicable.

\section{Declarations}

Ethics approval This study was approved by ethics committee of the Kerman University of Medical Sciences (IR.KMU.REC.1398.576).

Consent to participate Not applicable.

Consent for publication All authors agree to the publication in this journal.

Conflict of interest The authors declare competing interests.

\section{References}

Abbasi S, Keshavarzi B, Moore F, Hopke PK, Kelly FJ, Dominguez AO (2020) Elemental and magnetic analyses, source identification, and oxidative potential of airborne, passive, and street dust particles in Asaluyeh County, Iran. Science of The Total Environment 707:136132

Aguilera A, Bautista F, Gutiérrez-Ruiz M, Ceniceros-Gómez AE, Cejudo R, Goguitchaichvili A (2021) Heavy metal pollution of street dust in the largest city of Mexico, sources and health risk assessment. Environ Monit Assess 193(4):1-16

Al-Khashman OA (2004) Heavy metal distribution in dust, street dust and soils from the work place in Karak Industrial Estate, Jordan. Atmos Environ 38(39):6803-6812 
Atapour H (2015) Geochemistry of potentially harmful elements in topsoils around Kerman city, southeastern Iran. Environ Earth Sci 74(7):5605-5624

Cesari D, Contini D, Genga A, Siciliano M, Elefante C, Baglivi F, Daniele L (2012) Analysis of raw soils and their re-suspended PM10 fractions: characterisation of source profiles and enrichment factors. Appl Geochem 27(6):1238-1246

Cesari D, Merico E, Grasso FM, Decesari S, Belosi F, Manarini F, De Nuntiis P, Rinaldi M, Volpi F, Gambaro A (2019) Source apportionment of PM2. 5 and of its oxidative potential in an industrial suburban site in south Italy. Atmosphere 10(12):758

Chirizzi D, Cesari D, Guascito MR, Dinoi A, Giotta L, Donateo A, Contini D (2017) Influence of Saharan dust outbreaks and carbon content on oxidative potential of water-soluble fractions of PM2.5 and PM10. Atmos Environ 163:1-8

Dytłow, S. and B. Górka-Kostrubiec (2020). "Concentration of heavy metals in street dust: an implication of using different geochemical background data in estimating the level of heavy metal pollution." Environ Geochem Health: 1-15.

Ferrante M, Fiore M, Conti GO, Fiore V, Grasso A, Copat C, Signorelli SS (2017) Transition and heavy metals compared to oxidative parameter balance in patients with deep vein thrombosis: a case-control study. Mol Med Rep 15(5):3438-3444

Gao D, Godri Pollitt KJ, Mulholland JA, Russell AG, Weber RJ (2020) Characterization and comparison of PM 2.5 oxidative potential assessed by two acellular assays. Atmos Chem Phys 20(9):5197-5210

Godri KJ, Duggan ST, Fuller GW, Baker T, Green D, Kelly FJ, Mudway IS (2010) Particulate matter oxidative potential from waste transfer station activity. Environ Health Perspect 118(4):493-498

Hamzeh MA, Aftabi A, Mirzaee M (2011) Assessing geochemical influence of traffic and other vehicle-related activities on heavy metal contamination in urban soils of Kerman city, using a GISbased approach. Environ Geochem Health 33(6):577

Islam MT (2017) Oxidative stress and mitochondrial dysfunctionlinked neurodegenerative disorders. Neurol Res 39(1):73-82

Jantzen K, Jensen A, Kermanizadeh A, Elholm G, Sigsgaard T, Møller P, Roursgaard M, Loft S (2018) Inhalation of house dust and ozone alters systemic levels of endothelial progenitor cells, oxidative stress, and inflammation in elderly subjects. Toxicol Sci 163(2):353-363

Kelly, F., H. R. Anderson, B. Armstrong, R. Atkinson, B. Barratt, S. Beevers, D. Derwent, D. Green, I. Mudway and P. Wilkinson (2011). "The impact of the congestion charging scheme on air quality in London. Part 1. Emissions modeling and analysis of air pollution measurements." Research Report (Health Effects Institute)(155): 5-71.

Khaniabadi YO, Fanelli R, De Marco A, Daryanoosh SM, Kloog I, Hopke PK, Conti GO, Ferrante M, Mohammadi MJ, Babaei AA (2017) Hospital admissions in Iran for cardiovascular and respiratory diseases attributed to the Middle Eastern Dust storms. Environ Sci Pollut Res 24(20):16860-16868

Konstantinova, E., T. Minkina, A. Konstantinov, S. Sushkova, E. Antonenko, A. Kurasova and S. Loiko (2020). "Pollution status and human health risk assessment of potentially toxic elements and polycyclic aromatic hydrocarbons in urban street dust of Tyumen city, Russia." Environ Geochem Health: 1-24.

Lin P, Yu JZ (2011) Generation of reactive oxygen species mediated by humic-like substances in atmospheric aerosols. Environ Sci Technol 45(24):10362-10368

Lionetto MG, Guascito MR, Caricato R, Giordano ME, De Bartolomeo AR, Romano MP, Conte M, Dinoi A, Contini D (2019) Correlation of oxidative potential with ecotoxicological and cytotoxicological potential of PM10 at an urban background site in Italy. Atmosphere 10(12):733
Lu X, Shi D, Yin N, Pan H, Smith P (2017) Risk assessment of heavy metals in finer than 63- $\mu \mathrm{m}$ dust particles from various functional areas in Xi' an, China. Air Qual Atmos Health 10:907-915

Ma Y, Cheng Y, Qiu X, Cao G, Fang Y, Wang J, Zhu T, Yu J, Hu D (2018) Sources and oxidative potential of water-soluble humiclike substances (HULISWS) in fine particulate matter (PM2.5) in Beijing. Atmos Chem Phys 18(8):5607-5617

Malakootian M, Mohammadi A, Nasiri A, Asadi AMS, Conti GO, Faraji M (2021) Spatial distribution and correlations among elements in smaller than $75 \mu \mathrm{m}$ street dust: ecological and probabilistic health risk assessment. Environ Geochem Health 43(1):567-583

Manigrasso M, Simonetti G, Astolfi ML, Perrino C, Canepari S, Protano C, Antonucci A, Avino P, Vitali M (2020) Oxidative potential associated with urban aerosol deposited into the respiratory system and relevant elemental and ionic fraction contributions. Atmosphere 11(1):6

Massimi L, Ristorini M, Simonetti G, Frezzini MA, Astolfi ML, Canepari S (2020) Spatial mapping and size distribution of oxidative potential of particulate matter released by spatially disaggregated sources. Environ Pollut 266:115271

Mohammadi A, Faraji M, Conti GO, Ferrante M, Miri M (2019) Mortality and morbidity due to exposure to particulate matter related to drying Urmia Lake in the NW Iran. Eur J Intern Med 60:e14-e15

Moradi, Q., R. Mirzaei, M. Alipour, A. Bay, M. Ghaderpoori, A. Asadi, Y. Fakhri, A. Sorooshian and A. Mousavi Khaneghah (2020). "The concentration, characteristics, and probabilistic health risk assessment of potentially toxic elements (PTEs) in street dust: a case study of Kashan, Iran.” Toxin reviews: 1-10.

Naraki H, Keshavarzi B, Zarei M, Moore F, Abbasi S, Kelly FJ, Dominguez AO, Jaafarzadeh N (2021) Urban street dust in the Middle East oldest oil refinery zone: oxidative potential, source apportionment، and health risk assessment of potentially toxic elements. Chemosphere 268:128825

Nematollahi MJ, Dehdaran S, Moore F, Keshavarzi B (2020) "Potentially toxic elements and polycyclic aromatic hydrocarbons in street dust of Yazd, a central capital city in Iran: contamination level, source identification, and ecological-health risk assessment." Environ Geochem Health: 1-35.

Osorio-Martinez J, Silva LF, Flores EM, Nascimento MS, Picoloto RS, Olivero-Verbel J (2021) Environmental and human health risks associated with exposure to hazardous elements present in urban dust from Barranquilla, Colombian Caribbean, Wiley Online Library.

Pant P, Baker SJ, Shukla A, Maikawa C, Pollitt KJG, Harrison RM (2015) The PM10 fraction of road dust in the UK and India: characterization, source profiles and oxidative potential. Sci Total Environ 530:445-452

Patchaiyappan A, Dowarah K, Ahmed SZ, Prabakaran M, Jayakumar S, Thirunavukkarasu C, Devipriya SP (2021) Prevalence and characteristics of microplastics present in the street dust collected from Chennai metropolitan city, India. Chemosphere 269:128757

Pietrogrande MC, Perrone MR, Manarini F, Romano S, Udisti R, Becagli S (2018) PM10 oxidative potential at a Central Mediterranean Site: association with chemical composition and meteorological parameters. Atmos Environ 188:97-111

Rezaei S, Naddafi K, Hassanvand MS, Nabizadeh R, Yunesian M, Ghanbarian M, Atafar Z, Faraji M, Nazmara S, Mahmoudi B, Ghanbari Ghozikali M, ghanbarian M, Gholampour A (2018) "Physiochemical characteristics and oxidative potential of ambient air particulate matter (PM10) during dust and non-dust storm events: a case study in Tehran, Iran.” Journal of Environmental Health Science and Engineering Online publish.

Safiur Rahman M, Khan MDH, Jolly YN, Kabir J, Akter S, Salam A (2019) Assessing risk to human health for heavy metal 
contamination through street dust in the Southeast Asian Megacity: Dhaka, Bangladesh. Sci Total Environ 660:1610-1622

Santo Signorelli S, Conti GO, Zanobetti A, Baccarelli A, Fiore M, Ferrante $M$ (2019) Effect of particulate matter-bound metals exposure on prothrombotic biomarkers: a systematic review. Environ Res $177: 108573$

Shi D, Lu X (2018) Accumulation degree and source apportionment of trace metals in smaller than $63 \mu \mathrm{m}$ road dust from the areas with different land uses: a case study of Xi' an, China. Sci Total Environ 636:1211-1218

Singh A, Kukreti R, Saso L, Kukreti S (2019) Oxidative stress: a key modulator in neurodegenerative diseases. Molecules 24(8):1583

Statistical, Center, of, Iran., Natinal, Portal, of, Statistics:, Population, census, and and housing. (2016). Retrieved Accessed on 21 June 2019, from https://www.amar.org.ir/.

Taghavi, S. N., H. Kamani, M. H. Dehghani, R. Nabizadeh, N. Afshari and A. H. Mahvi (2019). "Assessment of heavy metals in street dusts of Tehran using enrichment factor and geo-accumulation index." Health Scope 8(1).
Wang P, Xue J, Zhu Z (2021) "Comparison of heavy metal bioaccessibility between street dust and beach sediment: particle size effect and environmental magnetism response." Sci Total Environ 146081.

Yang A, Jedynska A, Hellack B, Kooter I, Hoek G, Brunekreef B, Kuhlbusch TA, Cassee FR, Janssen NA (2014) Measurement of the oxidative potential of PM2. 5 and its constituents: the effect of extraction solvent and filter type. Atmos Environ 83:35-42

Yanosky JD, Tonne CC, Beevers SD, Wilkinson P, Kelly FJ (2012) Modeling exposures to the oxidative potential of PM10. Environ Sci Technol 46(14):7612-7620

Publisher's note Springer Nature remains neutral with regard to jurisdictional claims in published maps and institutional affiliations. 